\title{
Plant polyphenolic extracts as potential anti-human hepatocarcinoma agents
}

\author{
Maria Julia Martinez ${ }^{1}$, Adriana Andreu ${ }^{1}$ and Luciana Barbini ${ }^{2}$ 四
}

\begin{abstract}
Plant polyphenols are secondary metabolites, primarily synthesized to protect plants from biotic and abiotic stresses. These compounds are found in fruits, vegetables and beverages and are an important part of the human diet. Plant derived polyphenols have been described as antioxidant, antimicrobial and anticarcinogenic agents. Human hepatocellular carcinoma is one of the most common types of cancer worldwide and it is associated to high mortality. The development of new treatments for hepatocarcinoma is needed, and plant polyphenols appear as a promising important source of compounds for prevention and treatment of this disease. The aim of this article is to review the current knowledge about the use of plant polyphenolic extracts as potential agents for the treatment of human hepatocellular carcinoma.
\end{abstract}

Keywords: polyphenolic plant extracts; anti-human hepatocarcinoma; in vitro assay; in vivo animal test

\section{Introduction}

Plant polyphenols are a wide group of secondary metabolites. Their main function is to protect the plant from biotic and abiotic stresses, such as herbivores,

Received: 15 May 2014

Accepted revised version: 16 August 2014

Published online: 06 October 2014

(C) Martinez, M. J., Andreu, A. \& Barbini, L. (2014)

Publisher: Horizon e-Publishing Group

\section{CITATION}

Martinez, M. J., Andreu, A. and Barbini, L. (2014). Plant polyphenolic extracts as potential anti-human hepatocarcinoma agents. Plant Science Today, 1(4), 213-218. http://dx.doi.org/10.14719/pst.2014.1.4.62

\section{AUTHOR'S AFFILIATION}

1 Instituto Investigaciones Biológicas, Universidad Nacional de Mar del Plata, Dean Funes 3350, Mar del Plata, Argentina.

2 Catedra de Microbiologia Clínica, Departamento de Química, Universidad Nacional de Mar del Plata, Dean Funes 3350, Mar del Plata, Argentina.

CORRESPONDENCE

凶Dr. Luciana Barbini, e-mail: lbarbini@yahoo.com photosynthetic stress, reactive oxygen species, wounds and UV radiation (Yang, Landau, Huang, \& Newmark, 2001; Stagos et al., 2012). These compounds are classified according to their chemical structure into two major groups: flavonoids and non-flavonoids. The first group include: flavanols, flavonols, anthocyanidins, flavones, flavanones and chalcones. The non-flavonoids are divided into: stilbenes, lignans and phenolic acids (D' Archivio, Filesi, Di Benedetto, Gargiulo, \& Masella, 2007; Stagos et al., 2012). These metabolites are constituents of a great variety of fruits, vegetables and beverages and represent an essential part of the human diet (Ramos, Alia, Bravo, \& Goya, 2005; Leifert \& Abeywardena, 2008; Wang et al., 2011; Darvesh \& Bishayee, 2013).

In the past decade, scientists have focused their research on polyphenols and their beneficial effects on human health. Many biological activities as antioxidants (Kim, Quon, \& Kim, 2014), antiinflammatories (Lee et al, 2014), antimicrobials (Daglia, 2012), neuroprotectives (Oboh, Agunloye, Akinyemi, Ademiluyi, \& Adefegha, 2012) and anticarcinogenic (Yang et al., 2001) were widely described for polyphenols. Furthermore, several epidemiological studies have shown a correlation between regular fruit and vegetables consumption and a lower incidence of certain chronic diseases, such as cardiovascular disease or cancer (Ortega, 2006; Jin, Zheng, \& Li, 2008).

Hepatocellular carcinoma (HCC) is one of the most frequent tumors worldwide and is associated to high mortality (Okuda, 2000; Feitelson et al., 2002). There are different risk factors related to HCC development, as chronic hepatitis B virus (HBV) and hepatitis $C$ virus (HCV) infections, chronic exposure to mycotoxins, aflatoxin $\mathrm{B}$, and alcoholic cirrhosis (Feitelson et al., 2002). The geographical areas at the highest risk for HCC development are South East Asia and sub Saharan Africa, where HBV infection is highly endemic and the main cause of HCC (Pang, Tse, \& Poon, 2006).

The different treatments for HCC are divided into curative and palliative. The curative treatments include resection, liver transplantation and percutaneous ablation. 
These treatments are expected to improve patients' survival, but they are only applicable to a small proportion of them with early tumors (Pang et al., 2006). Palliative treatments, as chemoembolisation, are applied to patients with advanced HCC (Llovet, Burroughs, \& Bruix 2003). Although actually sorafenib (a multikinase inhibitor) or hepatic artery infusion chemotherapy are available treatments, the life expectancy of the treated patients remains low and persons with a late HCC diagnosis have very poor possibilities (Song \& Bae, 2014; Rasool et al., 2014).

In this scenario, new antitumoral drugs are really needed, appearing natural compounds as an important source of new molecules to be used for the prevention and treatment of HCC. In consequence, many researchers are focused on the investigation of the antitumoral activity of natural polyphenols. The main objective of this article is to summarize the current knowledge about the in vitro and in vivo antitumoral activity of natural polyphenolic extracts (PE), as potential human antihepatocarcinoma agents.

\section{Natural Polyphenolic Extracts: Biologic activity in human hepatocarcinoma in vitro and in vivo models}

Plant polyphenols activity has been largely studied against several types of human cancers such as colon, prostate and breast (Nzaramba, Reddivari, Bamberg, \& Miller Jr, 2009; Thakur, Gupta, \& Gupta, 2012; Sahpazidou et al., 2014). In the particular case of HCC, there are a great number of publications about different effects of polyphenols against this disease. This anti human hepatocarcinoma activity has been described for several PE from commonly consumed fruits, vegetables and beverages (Sun, Chu, Wu, \& Liu, 2002; Chu, Sun, Wu \& Liu, 2002; Ramos et al., 2005; Wang et al., 2011); but also, for many autochthonous herbs used in traditional medicine (Naowaratwattana, De-Eknamkul, \& De Mejia, 2010; Sawadogo, Schumacher, Teiten, Dicato, \& Diederich, 2012; Sakulnarmrat, Fenech, Thomas, \& Konczak, 2013). Tables (supplementary material) summarize the biological activity of a variety of PE in different in vitro (Table 1) or in vivo (Table 2) models and the solvents used for extractions of the phenolic compounds.

\section{In vitro assay}

In vitro assays using the human hepatocarcinoma cell line HepG2, showed that PE from vegetables consumed worldwide (broccoli, spinach, carrot, potato and lettuce) exerted significant cytotoxic activity after a 96 hours treatment (Chu et al., 2002; Wang et al., 2011). Treatments with PE from different kinds of fruits, such as strawberries and plums, were also tested as anti-HCC agents. These PE produced an inhibition of HepG2 cells proliferation, possibly through the activation of apoptosis (Ramos et al., 2005). Naowaratwattana et al. (2010), investigated the effect of four different mulberry extracts (aqueous, 100\% methanol, 50\% methanol and 1-butanol) on the HepG2 cell line. Although, all the assayed extracts reduced cell viability, the organic extracts showed more cytotoxic activity than the aqueous ones. A similar anti-proliferative effect in HepG2 cells was also described for other plant species such as Lonicera japonica Thunb (Park et al., 2011), Pulsatilla koreana (Hong et al., 2012), Oryza sativa (Banjerdpongchai, Wudtiwai, \& Sringarm, 2013), Costus speciosus (Nair, Hettihewa, \& Rupasinghe, 2014).

Tea consumption has been widely associated to hepatoprotective activity. Many groups have been studying the biological activity of tea polyphenols, particularly of epigallocatechin gallate (EGCG), the main polyphenolic compound of the tea. EGCG activity against HCC included anti-proliferative, cell cycle arrest and induction of apoptosis (Darvesh \& Bishayee, 2013). Newell, Yousef, Lila, \& Ramirez-Mares (2010) studied the anti-cancer potential of ardisia tea extracts from six different Ardisia species. All of them were cytotoxic for the HepG2 cell line and induced cell arrest in G1 phase of the cell cycle. These results show that ardisia tea anti-HCC activity is related to the cell cycle arrest and apoptosis activation.

Although, most of the research publications related to PE and HCC use the HepG2 cell line model, there are other HCC lines (Hep3B, Huh-7, SK-Hep1, PLC/PRF/5) also used as a biological model (Lin, Ng, Hsu, Shieh, \& Chiang, 2004). Freise et al. (2011) treated four HCC cell lines (HepG2, Hep3B, Huh-7 and SK-Hep1) with aqueous extracts of Lindera obtusiloba, a plant species traditionaly used in Korean medicine to treat liver diseases. This aqueous extract not only reduced cell viability in all the tested cell lines, but also modulated the expression of proteins involved in angiogenesis. Hsu et al. (2007) studied the effect of Euchresta formosana radix (EFR), a plant used in traditional Chinese medicine, on Hep3B cells. The treatment with EFR ethanolic extracts resulted in the reduction of cell viability by activation of apoptosis and $\mathrm{S}$ phase arrest of the cell cycle. Dendropanax morbifera Léveille, is another important species used in folk medicine, and its anti-HCC effect was studied on Huh-7 cell line. The methanolic extract reduced cell viability, activated apoptosis and senescence, and affected cell migration (Hyun et al., 2013). This inhibitory effect on migration and invasion was also observed in SK-Hep1 cell line incubated with Pinus densiflora extracts (Lee et al., 2007).

\subsection{Mechanisms of action}

The main mechanism proposed for PE biological activity is the activation of programmed cell death or apoptosis. This death mechanism can be triggered through the intrinsic or the extrinsic pathways, and involve caspase activation (Kroemer et al., 2009). Several in vitro studies using the HepG2 cell line described how the apoptotic pathways can be regulated by PE's action. Wang et al. 
(2010) studied the effect of the PE from a native plant from Asia, Solanum nigrum (SNPE), on HepG2 cells. The 24 hours treatment with the extract resulted in a significant reduction of HepG2 viability and the activation of caspase 8, 9 and 3. The expression of apoptosis regulators of the Bcl-2 family (Bcl-2, antiapoptotic and Bid proapoptotic) was also affected by SNPE treatment. All these results suggest that SNPE induces apoptosis in vitro. Induction of apoptosis has also been described for other PE from plants used in traditional medicine. Pinus massoniana is another example of an Asian native plant whose PE was described to exert anti-HCC activity. Bark PE of this plant (PMBE) reduced HepG2 viability after a 48 hours treatment. This cytotoxicity was related to the induction of cell cycle arrest in $\mathrm{G} 2 / \mathrm{M}$ phase, the activation of caspases 8,9 , and 3 , the downregulation of Bcl-2 and cleavage of Bid. Lonicera japonica Thunb. extract (LJE) treatment also induced apoptosis by the inhibition of Bcl-xL (an anti-apoptotic Bcl-2 family member) and the activation of Bak (a pro-apoptotic Bcl-2 family member). LJE also increased the activation of caspase 9 and 3, and the degradation of PARP (caspase 3 substrate) (Park et al., 2012).

Camellia species are endemic trees growing in Southern China. Yang et al. (2012) studied the effect of green coca tea (Camellia ptilophylla) extracts (GCTE) on HepG2 cells. A 72 hours treatment with GCTE inhibited cell growth in a dose dependent manner. Cells treated with GCTE were arrested at G0/G1 phase of the cell cycle, presented increased caspase 3 activity, up regulation of the cell cycle inhibitors p53, p21 and p27, increased expression of Bax and decreased Bcl-2. Furthermore, there are other plant species like Oryza sativa (Banjerdpongchai et al. 2013), Costus speciosus (Nair et al., 2014) and Morus alba L. (Naowaratwattana et al., 2010) extracts that reduce viability of HepG2 cell line in vitro, via the activation of caspases, leading to apoptotic cell death.

The induction of programmed cell death caused by PE has been extensively studied, but there are other mechanisms that can be modulated by the treatment with PE. Autophagic cell death is characterized by the absence of chromatin condensation accompanied by massive autophagic vacuolization of the cytoplasm (Kroemer et al., 2009). Lin et al. (2007), described the activation of autophagy after the treatment with Solanum nigrum polyphenolic extract (SNPE). SNPE increased levels of autophagic vacuoles, stimulated the accumulation of LC3 and the conversion of LC3-I to its autophagosome associated form, LC3-II. This treatment also resulted in the modulation of the signalling pathways that regulate autophagy and the down regulation of Bcl-2 and Akt, which are associated to the activation of autophagy.

Angiogenesis and metastasis are two essential processes for cancer development. Some PE has been characterized to exert their anti-HCC effect by blocking the formation of new vascular vessels and by the inhibition of invasion and migration capability. For example, Lindera obtusiloba extracts reduced invasive potential of treated cells and modulated the expression of proteins involved in angiogenesis, like VEGF and HIF-1 $\alpha$. Freiser and collaborators (2011) also studied some transcriptional factors and genes implicated in angiogenesis. The expression of the transcription factor PPAR $\gamma$ and the genes COX-2 and iNOS were inhibited after treatment with Lindera obtusiloba extracts. The anti-angiogenic effect was also described for Pulsatilla koreana extracts in treated Huh-7 cells that showed inhibition of the expression of VEGF and HIF-1 $\alpha$. This extract also affected migration of the treated cells (Hong et al., 2012). Also other plant extracts like Pinus densiflora (Lee et al., 2007) and Saussurea involucrate (Byambaragchaa, de la Cruz, Yang, \& Hwang, 2013) induced a reduction in the migration and invasion capability of cells. In both cases, the extracts inhibited the expression of MMP-2 and MMP-9, two extracellular matrix degrading proteinases, involved in migration.

\section{In vivo animal tests}

Several researchers have studied the effect of PE using in vivo hepatocellular carcinoma models. Most of them used rats or mice with chemically induced or tumor xenograft implanted HCC. Some of the PE mentioned in the in vitro section were also tested in vivo. For example, the effect of SNPE in the development of tumors was studied in athymic nude mice. HepG2 cells where implanted and mice with developed tumors where treated with SNPE for 35 days. SNPE consumption produced a $90 \%$ reduction in tumor weight and volume, compared to mice without treatment (Wang et al., 2010). The tumor xenograft model was also used to demonstrate the effect of PMBE in vivo. In this work, mouse hepatocellular carcinoma H22 cell line was implanted in Kunming mice and treatments were initiated 24 hours after injection of tumor cells. After 12 days of PMBE administration, mice treated showed a significant reduction in tumor growth (Ma et al., 2010). The in vivo effect of GCTE was studied in BALB/c nude mice, injected subcutaneously with HepG2 cells and treated 5 days after implantation. GCTE treatment for 27 days resulted in tumor growth inhibition, caspase 3 activation and DNA fragmentation.

Taken together, these results demonstrated that SNPE, PMBE and GCTE not only inhibited cell proliferation in vitro but also suppressed tumor growth in vivo. In vivo studies have also used ardisia species extracts to investigate their effect in liver carcinogenesis. Particularly, the activity of Ardisia compressa leaves extracts was evaluated in drug induced liver carcinogenesis in Wistar rats. The treatment inhibited the development and progression of tumors (Gonzalez de Mejia, Ramirez-Mares, Arce-Popoca, Walling, \& Villa-Trevio, 2004). Amin, Koh, \& 
Asmah (2004) studied the effect of other commonly consumed beverage extracts in rats with induced hepatocarcinoma. The treatment with Cacao liqueur extracts (CLE) of tumor induced in Sprague Dawley rats, resulted in a reduction of tumor marker enzymes in plasma and liver. This finding suggests that CLE may have a potential effect in reducing severity of hepatocarcinogenesis.

\section{Conclusions}

The evidences summarized in this article from in vivo and in vitro studies demonstrate that plant polyphenols are a promising good source to find new candidate molecules to be used for the prevention and treatment of HCC. Although, more in vivo experiments are needed to completely understand the mechanisms of action of these compounds in the inhibition of HCC. Also, it is extremely important to study and consider the bioavailability and stability of these compounds once they are absorbed in vivo. This would help to estimate, for example the daily consumption needed of certain food to exert their preventive effect or the necessary doses of polyphenolic compounds to act as antiHCC agents.

Another important aspect to consider is that polyphenolic extracts are a mixture of different molecules. Although, many studies are conducted to isolate and characterize the active compound responsible for the biological activity of the polyphenolic extract, it is necessary to consider that whole extracts may act synergically, being involved in the modulation of multiple intracellular pathways. As hepatocellular carcinoma is a complex disease, with multiple molecular mechanisms involved in its development, polyphenolic extracts would provide a wide spectrum of compounds capable of targeting different molecular pathways for treatment.

\section{References}

Amin, I., Koh, B.K., Asmah, R. (2004). Effect of Cacao liquior extract on tumor marker enzymes during chemical hepatocarcinogenesis in rats. Journal of medicinal food, 7: 7-12. http://dx.doi.org/10.1089/109662004322984635, PMID: 15117546.

Banjerdpongchai, R., Wudtiwai, B., Sringarm, K. (2013). Cytotoxic and apoptotic inducing effects of purple rice extracts and chemotherapeutic drugs on human cancer cell lines. Asian Pacific Journal of Cancer Prevention, 14: 6541-6548. PMID: 24377565.

Byambaragchaa, M., de la Cruz, J.,Yang, S.H., Hwang, S.G. (2013). Antimetastatic potential of etanol extract of Saussurea involucrata against hepatic cáncer in vitro. Asian Pac J Cancer Prev., 14: 5397-402, PMID: 24175833.

Chu, Y.F., Sun, J., Wu, X., Liu, R.H. (2002). Antioxidant and antiproliferative activities of common vegetables. Journal of agricultural and food chemistry. 50: 6910-6916. http://dx.doi.org/10.1021/jf020665f, PMID: 12405796.

Daglia, M. (2012). Polyphenols as antimicrobial agents. Current Opinion in Biotechnology, 23:174-181. http://dx.doi.org/10.1016/j.copbio.2011.08.007, PMID: 21925860.

D' Archivio, M., Filesi, C., Di Benedetto, R., Gargiulo, C.G., Masella, R. (2007). Polyphenols, dietary sources and bioavailability. Ann Ist super Sanità, 43: 348-361, PMID: 18209268.

Darvesh, A.S., Bishayee, A. (2013). Chemopreventive and therapeutic potential of tea polyphenols in hepatocellular cancer. Nutrition and Cancer, 65: 329-344. http://dx.doi.org/10.1080/01635581.2013.767367, PMID: 23530632.

Feitelson, M.A., Sun, B., Tufan, N.L.S., Liu, J., Pan, J., Lian, Z. (2002). Genetic mechanisms of hepatocarcinogenesis. Oncogene, 21: 2593-2604. http://dx.doi.org/10.1038/sj/onc/1205434, PMID: 11971194.

Freise, C., Ruehl, M., Erben, U., Neumann, U., Seehofer, D., Kim, K.Y., ... Somasundaram, R. (2011). A hepatoprotective Lindera obtusiloba extract suppresses growth and attenuates insulin like growth factor 1 receptor signaling and NF-kappaB activity in human liver cancer cell line. BMC Complement $\quad$ Altern $\quad 39$. http://dx.doi.org/10.1186/1472-6882-11-39, PMID: 21569410.

Gonzalez de Mejia, E., Ramirez-Mares, M.V., Arce-Popoca, E., Walling, M., Villa-Trevio, S. (2004). Inhibition of liver carcionogenesis in Wistar rats by consumption of an aqueous extract from leaves of Ardisia compressa. Food and Chemical Toxicology, 42: 509-516. http://dx.doi.org/10.1016/j.fct.2003.10.016, PMID: 14871594.

Gul, M.Z., Ahmad, F., Kondapi, A.K., Qureshi, I.A., Ghazi, I.A. (2013). Antioxidant and antiproliferative activities of Abrus precatorius leaf extracts an in vitro study. Complementary and alternative medicine, 13. http://dx.doi.org/10.1186/1472-6882-13-53, PMID: 23452983.

Hong, S.W., Jung, K.H., Lee, H.S., Choi, M.J.,Zheng, H.M., Son, M.K., ... Hong, S.S. (2012). Apoptotic and antiangiogenic effects of Pulsatilla koreana extract on hepatocellular carcinoma. Int J Oncol. 40: 452-60. http://dx.doi.org/10.3892/ijo.2011.1204, PMID: 2193557.

Hsu, S.C., Kuo, C.L., Lin, J.P., Lee, J.H., Lin, C.C., Su, C.C., ... Chung, J.G. (2007). Crude extracts of Euchresta formosanaradix induce cytotoxicity and apoptosis in human hepatocellular carcinoma cell line (Hep3B). Anticancer Res. 27: 2415-25, PMID: 17695533.

Hyun, T.K., Kim, M.O., Lee, H., Kim, Y., Kim, E., Kim, J.S. (2013). Evaluation of anti-oxidant and anti-cancer properties of Dendropanax morbifera Léveille. Food Chem. 141: 1947-55. http://dx.doi.org/10.1016/j.foodchem.2013.05.021, PMID: 23870914.

Jin, X., Zheng, R., Li, Y. (2008). Green tea consumption and liver disease: a systematic review. Liver international, 28: 990-996. http://dx.doi.org/10.1111/j.1478-3231.2008.01776.x, PMID: 18482271.

Kim, H.J., Han, M.H., Kim, G.Y., Choi, Y.W., Choi, Y.H. (2012). Hexane extracts of garlic cloves induce apoptosis through the generation of reactive oxygen species in Hep3B human hepatocarcinoma cells. Oncol Rep. 28: 1757-63. http://dx.doi.org/10.3892/or.2012.1985, PMID:22923154.

Kim, H.S., Quon, M.J., Kim, J. (2014). New insights into the mechanisms of polyphenols beyond antioxidant properties; lessons from the green tea polyphenols, 
epigallocatechin-3-gallate. Redox Biology, 2: 187-195. http://dx.doi.org/10.1016/j.redox.2013.12.022, PMID: 24494192.

Kroemer, G., Galluzzi, L., Vandenabeele, P., Abrams, J., Alnemri, E.S., Baehrecke, E.H., ... Melino, G. (2009). Classification of cell death: recommendations of the Nomenclature Committee on Cell Death 2009. Cell Death Differ. 16: 3-11. http://dx.doi.org/10.1038/cdd.2008.150.

PMID: 18846107.

Lee, S.J., Lee, K.W., Hur, H.J., Chun, J.Y., Kim, S.Y., Lee, H.J. (2007). Phenolic phytochemicals derived from red pine (Pinus densiflora) inhibit the invasion and migration of SK-Hep-1 human hepatocellular carcinoma cells. Ann N Y Acad Sci. 1095: 536-44, PMID: 17404067.

Lee, S.G., Kim, B., Yang, Y., Pham, T.X, Park Y.K., Manatou, J., ... Lee, J.Y. (2014). Berry anthocyanins suppress the expression and secretion of proinflammatory madiators in macrophages by inhibiting nuclear translocation of NF-kB independent of NRF2-mediated mechanisms. Journal of Nutritional Biochemistry, 25: 404-411. http://dx.doi.org/10.1016/j.jnutbio.2013.12.001, PMID: 24565673.

Leifert, W., Abeywardena, M.Y. (2008). Grape seed and red wine polyphenols extracts inhibit cellular choloesterol uptake, cell proliferation, and 5-lipoxygenase activity. Nutrition Research, 28: 842-850. http://dx.doi.org/10.1016/j.nutres.2008.09.001, PMID: 19083497.

Lin, C.C., Ng, L.T., Hsu, F.F., Shieh, D.E., Chiang, L.C. (2004). Cytotoxic effects of Coptis chinensis and Epimedium sagittatum extracts and their major constituents (berberine, coptisine and icariin) on hepatoma and leukaemia cell growth. Clin Exp Pharmacol Physiol. 31: 65-9. http://dx.doi.org/10.1111/j.1440-1681.2004.03951.x, PMID:14756686.

Lin, H.M., Tseng, H.C., Wang, C.J., Chyau, C.C., Liao, K.K, Peng, P.L., Chou, F.P. (2007). Induction of autophagy and apoptosis by the extract of Solanum nigrum Linn in HepG2 cells. Journal of agricultural and food chemistry, 55: 3620-3628. http://dx.doi.org/10.1021/jf062406m, PMID: 17419635.

Llovet, J.M, Burroughs, A., Bruix, J. (2003). Hepatocellular carcinoma. Lancet, 362: 1907-1917. http://dx.doi.org/10.1016/S0140-6736(03)14964-1, PMID: 14667750.

Ma, H., Liu, B., Feng, D., Xie, D., Li, R., Yuchi, Y., ... Wang, J. (2010). Pinus massoniana bark extract selectively induces apoptosis in human hepatoma cells, possibly through caspase-dependent pathways. International Journal of Molecular Medicine, 25: 751-759. doi 10.3892/ijmm_00000401, PMID: 20372819.

Nair, S.V., Hettihewa, M., Rupasinghe, H.P. (2014). Apoptotic and inhibitory effects on cell proliferation of hepatocellular carcinoma HepG2 cells by methanol leaf extract of Costus speciosus. Biomed Res Int. 2014: 637098. http://dx.doi.org/10.1155/2014/637098, PMID: 24818148.

Naowaratwattana, W., De-Eknamkul, W., De Mejia, E.G. (2010). Phenolic-containing organic extracts of mulberry (Morus alba L.) leaves inhibit HepG2 hepatoma cells through G2/M phase arrest, induction of apoptosis, and inhibition of topoisomerase IIa activity. J Med Food. 13: 1045-56. http://dx.doi.org/10.1089/jmf.2010.1021,

PMID: 20828312 .

Newell, A.M.B., Yousef, G.G., Lila, M.A., Ramirez-Mares, M.V. (2010). Comparative in vitro bioactivities of tes extracts from six species of Ardisia and their effect on growth inhibition of HepG2 cells. Journal of ethnopharmacology, 130: 536-544. doi:10.1016/j.jep.2010.05.051, PMID: 20561930

Nzaramba, M.N., Reddivari, L., Bamberg, J.B., Miller Jr, J.C. (2009). Antiproliferative activity and cytotoxicity of Solanum jamessi tuber extracts on human colon and prostate cancer cells in vitro. Journal of agricultural and food chemistry, 57: 8308- 8315. http://dx.doi.org/10.1021/jf901567k, PMID: 19711917.

Oboh, G., Agunloye, O.M., Akinyemi, A.J., Ademiluyi, A.O., Adefegha, S.A. (2012). Comparative study on the inhibitory effect of caffeic and chlorogenic acids on key enzymes linked to Alzheimer's disease and some pro-oxidant induced oxidative stress in rats brain in vitro. Neurochem Res 38, 2: 413-419. doi:10.1007/s11064-012-0935-6, PMID:23184188.

Okuda, K. (2000). Hepatocellular carcinoma. Journal of Hepatology, 32, 225-237. PMID: 10728807.

Ortega, R.M. (2006). Importance of functional foods in the Mediterranean diet. Public Health Nutrition, 9: 1136-1140. PMID: 17378953.

Pang, R., Tse, E., Poon, R.T.P. (2006). Molecular pathways in hepatocellular carcinoma. Cancer letters, 240: 157-169. http://dx.doi.org/10.1016/j.canlet.2005.08.031, PMID: 16239065.

Park, H.S., Park, K.I., Lee, D.H., Kang, S.R., Nagappan, A., Kim, J.A., ... Kim, G.S. 2012. Polyphenolic extract isolated from Korean Lonicera japonica Thunb. Induce G2/M cell cycle arrest and apoptosis in HepG2 cells:involvemen ts of PI3K/Akt and MAPKs. Food Chem Toxicol. 50: 2407-16. http://dx.doi.org/10.1016/j.fct.2012.04.034, PMID: 22561682

Rajkumar, V., Guha, G., Kumar, R.A. (2011). Antioxidant and anti-neoplastic activities of Picrorhiza kurroa extracts. Food Chem Toxicol. 49: 363-9. http://dx.doi.org/10.1016/j.fct.2010.11.009, PMID: 21081148

Rajkumar, V., Guha, G., Kumar, R.A. (2011). Apoptosis induction in MDA-MB-435S, Hep3B and PC-3 cell lines by Rheumemodi rhizome extracts. Asian Pac J Cancer Prev. 12: 1197-200. PMID: 21875266.

Ramos, S., Alia, M., Bravo, L., Goya, L. (2005). Comparative effects of food-derived polyphenols on the viability and apoptosis of a human hepatoma cell line (HepG2). J. Agric. Food Chem., 53: 1271-1280. http://dx.doi.org/10.1021/jf0490798, PMID: 15713052.

Rasool, M., Rashid, S., Arooj, M., Ansari, S.A., Khan, K.M., Malik, A., ... Sheikh, I.A (2014). New possibilities in hepatocellular carcinoma treatment. Anticancer research, 34: 1563-1572. PMID: 24692683.

Sahpazidou D., Geromihalos, G.D., Stagos, D., Apostolou, A., Haroutounian, S.A., Tsatsakis, A.M., ... Kouretas, D. (2014). Anticarcinogenic activity of polyphenolic extracts from grape stems against breas, colon, renal and thyroid cancer cells. Toxicology letters. doi:10.1016/j.toxlet.2014.01.042, PMID: 24508987. 
Sakulnarmrat, K., Fenech, M., Thomas, P., Konczak, I. (2013). Cytoprotective and pro-apoptotic activities of native Australian herbs polyphenolic-rich extracts. Food Chem.136: 9-17. http://dx.doi.org/10.1016/j.foodchem.2012.07.089, PMID: 23017386.

Sawadogo, W.R., Schumacher, M., Teiten, M.H., Dicato, M., Diederich, M. (2012). Traditional West African pharmacopeia, plants and derived compounds for cancer therapy. Biochemical Pharmacology, 84: 1225-1240. doi :10.1016/j.bcp.2012.07.021, PMID: 22846603.

Shin, D.Y., Ryu, C.H., Lee, W.S., Kim, D.C., Kim, S.H., Hah, Y.S., Lee, S.J., Shin, S.C., Kang, H.S., Choi, Y.H. (2009). Induction of apoptosis and inhibition of invasion in human hepatoma cells by anthocyanins from Meoru. Annals of the New York Academy of Sciences, 1171: 137-148. http://dx.doi.org/10.1111/j.1749-6632.2009.04689.x, PMID: 19723048.

Singh, B.N., Singh, B.R., Sarma, B.K., Singh, H.B. (2009). Potential chemoprevention of N-nitrosodiethylamine-induced hepatocarcinogenesis by polyphenolics from Acacia nilotica bark. Chem Biol Interact., 181: 20-8. http://dx.doi.org/10.1016/j.cbi.2009.05.007, PMID: 19446540.

Song, M.J., Bae, S.H. (2014). Newer treatments for advanced hepatocellular carcinoma. Korean Journal of International Medicine, 29: 149-155. http://dx.doi.org/10.3904/kjim.2014.29.2.149, PMID: 24648795.

Stagos, D., Amougias, G., Matakos, A., Spyrou, A., Tsatsakis, A.M., \& Kouretas, D. (2012). Chemoprevention of liver cancer by plant polyphenols. Food and Chemical Toxicology, 50: 2155-2170. http://dx.doi.org/10.1016/j.fct.2012.04.002, PMID: 22521445.

Sun, J., Chu, Y, Wu, X., Liu, R.H. (2002). Antioxidant and antiproliferative activities of common fruits. Journal of Agricultural and food Chemistry, 50: 7449-7454. http://dx.doi.org/10.1021/jf0207530, PMID: 12452674.

Thakur, V.S., Gupta, K., Gupta, S. (2012). Green tea polyphenols causes cell cycle arrest and apoptosis in prostate cancer cells by suppressing class I histone deacetylases. International Journal of Oncology, 41: 353-361. http://dx.doi.org/10.3892/ijo.2012.1449, PMID: 22552582.

Wang, H.C., Chung, P.J., Wu, C.H., Lan, K.P., Yang, M.Y., Wang, C.J. (2010). Solanum nigrum L. polyphenolic extract inhibtis hepatocarcinoma cell growth by inducing G2/M phase arrest and apoptosis. Journal of Science of Food and Agriculture, 91: 178-185. http://dx.doi.org/10.1002/jsfa.4170, PMID: 20853273.

Wang, Q., Chen, Q., He, M., Mir, P., Su, J., Yang, Q. (2011). Inhibitory effect of antioxidant extract from various potatoes on the proliferation of human colon and liver cancer cells. Nutrition and Cancer, 63: 1044-1052. http://dx.doi.org/10.1080/01635581.2011.597538, PMID: 21888504.

Yang, C.S., Landau, J.M., Huang M.T., Newmark H.L. (2001). Inhibition of carcinogenesis by dietary polyphenolic compounds. Annu. Rev. Nutr, 21: 381-406. http://dx.doi.org/10.1146/annurev.nutr.21.1.381, PMID: 11375442.

Yang, M.Y., Hsu, L.S., Peng, C.H., Shi, Y.S., Wu, C.H., Wang, C.J. (2010). Polyphenol-rich extracts from Solanum nigrum attenuated PKC a-mediated migration and invasion of hepatocullular carcinoma cells. Journal of Agricultural and food chemistry, 58: 5806-5814. http://dx.doi.org/10.1021/jf100718b, PMID: 20349911.

Yang, X., Wang, Y.Y., La, K.K, Peng, L., Song, X., Shi, X., ... Ye, C. (2012). Inhibitory effects of cocoa tea (Camellia ptilophylla) in human hepatocellular carcinoma HepG2 in vitro and in vivo through apoptosis. Journal of Nutritional Biochemistry, 23: 1051-1057. http://dx.doi.org/10.1016/j.jnutbio.2011.05.010, PMID: 22018604.

Yu, M.H., Im, H.G., Kim, H.I., Lee, I.S. (2009). Induction of apoptosis by immature plum in human hepatocellular carcinoma. Journal of Medicinal Food, 12: 518-527. http://dx.doi.org/10.1089/jmf.2008.1268, PMID: 19627199.

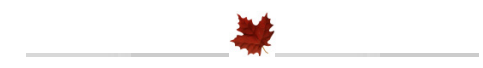

